\title{
Yaratıcı Endüstrilerin Yükselişi: Geçmiş, Bugün ve Gelecek
}

\author{
The Rise of Creative Industries: Past, Present and Future
}

\section{Dr. Gonca Aslan}

Başvuru Tarihi: 02.02.2016

Kabul Tarihi: 10.02.2017

\section{Öz}

Yaratıcı endüstriler, kısa bir süredir yönetim yazınında yer almakla birlikte, sanatçlar, ekonomistler, politika yapıcılar, akademisyenler gibi farklı paydaşlar tarafından önem atfedilen bir kavram olarak öne çıkmaktadir. Kavramın kültürel, yönetsel ve ekonomik unsurları içermesi nedeniyle, oldukça sofistike bir yapı ve "keşfedilmemiş topraklar" gibi bakir bir alan oluşturduğu anlaşılmaktadır. Yönetim ve organizasyon alanında yaratıcı endüstrilerin yeni yaklaşımlara, teori geliştirilmesine ve uygulamalara ihtiyaç duyduğu anlaşılmaktadır. Bu çalışmanın iki önemli amacı bulunmaktadır. Öncelikle, yaratıcı endüstriler kavramına ilişkin literatür incelenerek, Türk yönetim yazınında kavramla ilgili farkındalık yaratılmak istenmektedir. Bu bağlamda, yaratıcı endüstrilerin ne olduğu, yaratıcı endüstrilerin bilgi endüstrilerinden ne anlamda farklllaşttğı, kavramın sinıflandırılmasına ilişkin farkl yaklaşımlar ele alınmaktadır. Diğer bir amaç ise, gelecekte bu bakir alana araştırmacıların hangi alan ve bağlamda katkı sağlayabilecekleri konularında bir öngörü oluşturmaktır.

Anahtar Kelimeler: Yaratıcı Endüstriler, Kültür Endüstrileri, Yaratıcı Ekonomi, Yaratıcı Endüstriler Taksonomi

\begin{abstract}
Although being in its infancy, creative industries has become a prominent concept which has been attributed importance from different stakeholders such as artists, economists, policymakers and academicians. Because of comprising cultural, managerial and economic factors, creative industries constitute highly sophisticated yet "terra incognita" domain. In management and organization literature, creative industries is in need of new approaches, theory development and practical implications. In this study, there are two purposes: Primarily, is to review literature and raise awareness on thereanent. In this respect, the definition and scope of the concept, the difference between creative and knowledge industries and economies, different taxonomies on the subject will be discussed. Secondly, is to build opinion in what aspects and context researchers could contribute to the domain of creative industries.
\end{abstract}

Keywords: Creative Industries, Cultural Industries, Creative Economy, Creative Industries Taxonomy

Dr. Gonca Aslan, perlaaslan@gmail.com 


\section{Giriş}

Bilgi ve haberleşme teknolojilerinin hızla gelişmesi, geleneksel iş yapış yöntemlerini değiştirip dönüştürürken; bugüne dek tasarlanmamış iş alanlarının da gelişmesini ve beraberinde farklı meslek kollarının, insan kaynağının oluşmasını besleyen unsur olmuştur. Bu bağlamda, sanat ve yaratıcı alanların potansiyel birer iş kolu olarak pazarda kendisine yeni bir yer edinmesi ve politika uygulayıcılar tarafindan yaratıcı endüstriler kavramına önem atfedilmesi uzun sürmemiştir. Yeni iş alanları, yeni ekonomi, kültür ekonomisi, yaratıcı ekonomi olarak ifade edilen sanat ve yaratıcı alanların en belirgin özelliği, bilgi teknolojileri ile oldukça bütünleşmiş biçimde hareket ederek, küresel dünya pazarının tüm olanaklarından faydalanarak değer yaratmaları şeklinde ifade edilebilir. $\mathrm{Bu}$ bağlamda yaratıcı endüstrilerin yarattığı katma değer, hem mikro düzeyde (işletmeler) hem de makro düzeyde (bölgesel, ulusal ve uluslararası) önem arz etmektedir.

Özellikle son yirmi yıllık periyotta, yaratıcı endüstrilerin sosyal, ekonomik ve kültürel yaşam üzerindeki etkileri profesyoneller, akademisyenler, kamu kurumları ve politika yapıcılar tarafından yaygin olarak tartışılmaktadır. Yaratıcı endüstriler ile ilgili egemen görüş uzun bir süre kültür çalışmaları ekolünden, özellikle Frankfurt Okulu'nun devamı niteliğini taşıdığ 1 anlaşılmaktadır. Ancak son zamanlarda yapılan çalışmalarda yönetim ve ekonomi alanlarının ağırlı̆̆ daha fazla hissedilmektedir. Bunun nedeni, yaratıc1 endüstriler alanının yerel, bölgesel ve ulusal ekonomiye sağladığ 1 önemli katkıdan ileri geldiği anlaşımaktadır. Kuhncu terminoloji ile değerlendirilirse, paradigma öncesi dönemde olan yaratıcı endüstriler, konunun çekiciliği ve pratik alanlara sağladığı katkı nedeniyle pek çok verimli tartışmanın odak noktasinda yer almaktadır.

Yaratıcı endüstriler kavramı, etimolojik olarak değerlendirildiğinde, gömülü bir oksimoron nitelik taşıdığı anlaşılmaktadır. Çünkü yaratıcı endüstrilerde kullanıldı ̆̆ biçimde "yaratıcılık" daha çok sanat ve ilgili kültürel alanlardaki yaratıcılığa atıfta bulunmaktadır. Bu bağlamda, uzun yıllardan beri bilişsel olarak yapılandırdığımız şekliyle sanatsal ve kültürel alanlardaki yaratıcllık, maddi koşullar ya da bir endüstrileşme ile beraber anılmamaktadır. Daha çok bohem ve ticari kaygılardan arınmışlığa vurgu yapan yaratıcılı̆̆ın, yaratıcı endüstriler perspektifi ile birlikte farklı bir nite- lik kazandığını söylemek yanlış olmayacaktır. En eski insan faaliyetlerinden biri olan "yaratıcılık" ve 18.yy endüstri devrimi çıktısı "endüstri” kavramlarının bir araya gelmesi ile karakterize ve geç kapitalist periyotta öne çıkan yaratıcı endüstriler; oldukça sofistike bir ekonomik, kültürel ve sosyal yapı sergilemektedir. Bu bağlamda, yaratıcı endüstriler, arkaik insan faaliyeti olan "yaratıcıllk" ile görece insan için yeni bir faaliyet alanı ve üretim biçimi olan "endüstrileşme" kavramlarını bir araya getiren paradoksal bir olgu olarak karşımıza çıkmaktadır.

Sternberg ve Lubart $(1999$, s.3), yaratıcilığ hem alışılmamış (orijinal, beklenmedik) hem de uygun (kullanışlı, işin sınırlarına göre adapte edilebilen) iş üretebilme becerisi olarak tanımlamaktadırlar. Csikszentmihalyi (1988, s.325-326), yaratıcılığı her şeyden bağımsız bireysel bir eylem olmaktan öte bir noktada konumlandırmaktadır. Yazar; sosyal kurumların, bilgi alanının ve bireyin yaratıcılık eyleminin gerçekleşmesi için gerekli üç önemli güç olduğunun altını çizmektedir. Şüphesiz, yaratıcllığın her tür işte gerçekleşebileceğini belirten Hesmondhalgh ve Baker (2008, s.98), yaratıcı endüstriler alanının işyerindeki inovasyon ve imgelemi anlamak için öncelikli bir alan oluşturduğunu ifade etmektedirler. Von Osten (2007, s.51), yaratıcllık kavramının demokratikleşme ve modern bireyselliğin yükselişe geçtiği çağdaş kapitalist toplumlarda tutarsızlık gösterdiğini belirterek, yaratıcı endüstrilerin sosyal ve kültürel olanın teknoloji vasitasıyla endüstrileşmesi sonucunda oluştuğunu belirtmektedir. Diğer bir ifadeyle, yaratıcı işin ya da ürünün nasıl üretildiği, endüstri sözcügünün gizil anlamının etrafında çevrelenip tüketilmektedir (Townley vd., 2009, s.943-944).

Matheson (2006, s.58), yaratıcı endüstriler teorisinin önemli yaklaşımlar sunduğunu ve söz konusu teorinin ticari gerçekler ile kültürel ve yaratıcı çıktıları birleştirerek geniş bir çerçeve oluşturduğunun altını çizmektedir. Yaratıcı endüstriler alanındaki uygulayıcıların, küresel arenadaki ticari ve maddi gerçeklerle tanışık olduklarını belirten yazar, buna rağmen uygulayıcıların kültürel ve sosyal sorumluluklarının da farkında olduklarını öne sürmektedir. Yazar, yüksek kültür dışında kalan tüm kültürel aktivitelerin bu yolla demokratik yanlarının öne çıktığını iddia ederek, konuyla ilgili değerlendirme yapmaktadır. Burada yazarın referans gösterdiği, kültür ve sanatın post modern dünyada demokratikleşmesi ve yaratıcı endüstrilerin, 
yaratıcılık eyleminin ticarileşmesine işaret ederek bir anlamda demokratikleşme süreçlerine vurgu yaptığ 1 anlaşılmaktadır. Zamanın ruhuna (zeitgeist) uygun olarak; politik, kültürel ve teknolojik arenadaki gelişmeler doğrultusunda kendini yeniden üreten "yaratıcı endüstriler", post-endüstriyel toplumda meşrulaşarak kendini yeniden üretmektedir. Hartley'nin (2005), yaratıcı endüstriler kavramı ile ilgili çözümlemesi bu noktada dikkat çekici görünmektedir. Yazara göre kavram, ikili bir girişimi tanımlamaktadır; 1) kültürün temelinde hala yaratıcılık vardır, ancak; 2) yaratıcllık, endüstri toplumunda olduğundan farklı bir biçimde post-endüstriyel toplumda üretilmesi, yaygınlaşması, tüketilmesi ve keyif alınması bakımlarından dramatik farklılık göstermektedir.

Yaratıcı endüstriler; reklamcılık, mimarlık, tasarım, yazılım, film ve televizyon yapımı, müzik, fotoğrafçılık, yayıncılık ve sahne sanatları gibi iş kollarını kapsayan, genellikle yaratıcı öznenin emek girdisi ile karakterize edilen sektörlerin bütünü olarak ifade edilmektedir (NOIE, 2003). Artistik, yaratıcı ve entelektüel çabaların birleşmesi ile hayat bulan ürün ve hizmetleri tanımlayan yaratıcı endüstriler, kültürel ve ticari aktivitelerin kesiştiği bir alan olarak ifade edilmektedir (Turok, 2003, s.552). Caves (2000, s.1), yaratıcı endüstrileri; "ürün ve hizmetlerin kültürel, sanatsal veya eğlence değeri üzerinden ilişkili olan endüstriler" şeklinde tanımlamaktadır. Yazar söz konusu endüstrileri; kitap ve dergi yayıncılı̆̆ı, görsel sanatlar, sahne sanatları, sinema ve televizyon filmleri, moda endüstrisi, oyuncak endüstrisi ve bilgisayar oyunları şeklinde sinıflandırmaktadır. Tüm bu tanımlar göz önünde bulundurulduğunda, yaratıcı endüstrilerin fikri mülkiyet haklarına tabi telifli eserler ve ticari markalaşmış patentli materyalleri kapsayan tüm pratikleri ve enstitüleri işaret ettiği anlaşlmaktadir (Brouillette, 2008, s.122).

\section{Yaratıcı Endüstriler ve Kültür Endüstrileri Kavramları}

Yaratıcı endüstriler literatürü incelendiğinde, genellikle kavramın kültür endüstrileri kavramı ile eș anlamlı olarak kullanıldığı ve bu birbiri yerine kullanımın karmaşa yarattığı anlaşılmaktadır. Söz konusu karmaşa, hem epistemolojik hem de ontolojik olarak yaratıcı endüstrilerin anlaşılmasının ve alanda uygulama yapılmasının önünde engel teşkil etmektedir. $\mathrm{Bu}$ nedenle, öncelikle "kültür endüstrilerinin" ne anlam ifade ettiği, kültür endüstrileri eleştirisinin nasıl "kültürel endüstriler" söylemine dönüştüğü ve nihayet daha da rafineleşerek post-kapitalist söylemin içinde "yaratıcı endüstriler" olarak kendine yer edindiğinin tarihsel gelişimi açıklanarak, kavramlar arasındaki kargaşanın netleştirilmesi gerekmektedir.

Kültür endüstrileri kavramı, II. Dünya Savaşı sürecinde Avrupa Anakarasında yükselişe geçen faşist söylemler ve politik uygulamalar nedeniyle, Almanyayı terk etmek durumunda kalan düşünürler Adorno ve Horkheimer'ın Amerika kıtasına göçmeleri ve burada medya, kitle kültürü, eğlence, ideoloji alanlarına getirdikleri radikal eleştirel yaklaşımların bütününü ifade etmektedir. Bu bağlamda okulun üyeleri kültür endüstrileri kavramını, medyayı kitlelerin ideolojik iknası için mekanik yeniden üretim ve propaganda aracı olarak kullanan, sözde politikayı estetikleştiren faşist söylemlere karşı bir nefret söylemi olarak kullanmaktadırlar. Marksist temelden arındırılarak "kültür endüstrileri” kavramının yeniden politik sözlükte yer alması, 1970 ve 80 'lerin demokratik ve eşitlikçi politik söylemlerine denk gelmektedir.

Kültür ve sanatın ekonomik faydalarının, bölgesel, ulusal kalkınma ve refah üzerindeki rolünü algılayan politik organların; televizyon, müzik, film gibi popüler ticari endüstrileri "kültürel endüstriler" olarak markalaştırılarak, Devletin kültür politikalarını oluşturdukları anlaşılmaktadır (Hartley, 2005, s.1013). Yeni bir kavram olarak karşımıza çıkan yaratıcı endüstriler ise; sanat-kültür endüstrileri, özgürlükkonformite, kamu-özel teşebbüs, vatandaş-tüketici, politik-kişisel dikotomileri arasındaki bulanıklığ 1 kullanarak kendini derin bir post modern diyalektik içinde gerçekleştirmektedir. Garnham'da (2005, s.22), Avrupa Birliğiinin bilgi-temelli ekonomik gelişme söylemleri kapsamında oluşturulan yeni ekonomi ve kültürel politikalar neticesinde, kültür endüstrileri kavramının yerini yaratıcı endüstriler kavramına bıraktığını ve bu yolla Avrupảnın ekonomik anlamda rekabet edebilirliğinin garanti altına alınmasının temellerinin atıldığını ifade etmektedir.

Yaygın olarak kültürel endüstriler ve yaratıcı endüstriler kavramları eşanlamlı olarak kullanılsa da, kavramlar arasındaki farklılığı vurgulayan ender çalı̧̧alardan birinde Cunningham (2001, s.19-32), "kültür endüstrileri" kavramını tarihsel arka plan 
üzerinden değerlendirerek, temelinin sanat-ticaret ya da sanat-medya bağlantılandırmaları neticesinde oluştuğunu öne sürmektedir. Cunningham (2001, s.24) çözümlemesinde, dünya çapında ağ bağlantıları ve dijitalleşme gibi 20. yy'in son zamanlarında gerçekleşen birinci dalga teknolojik gelişmeler ile klasik anlamda kültür endüstrileri kavramının belirdiğini ifade etmektedir. İkinci dalga olarak bahsettiği teknolojilerin yeni ve yaratıcı uygulamalarıyla, büyük şirketlerin ürettiği bir eğlence ya da sanatın gerçek zamanlı tüketilmesine işaret eden kültür endüstrileri kavramının demode kaldığını belirtmektedir. Kitlesel olan üretim ve tüketimin önüne geçen yaratıcı endüstriler, küçük ve yaratıcı işletmelerin yeni iş modellerine ve inovatif pratiklerine işaret etmektedir (Cunningham, 2001, s.25).

Peltoniemi (2015, s.41-42), kültür endüstrilerine ilişkin incelediği 314 makale sonucunda, şöyle bir tanıma ulaşmaktadır: "İçerisinde yaratıcı unsurlar içeren ve tüketici pazarına kitlesel dağıtım kanalıyla ulaşmayı hedefleyen deneyimsel ürünler üreten endüstriler kültür endüstrileridir". Yazar tanımlamasını detaylandırarak yaratıcı unsurların eğlence, kimlik inşası ve sosyal sunuma hizmet eden hikayeler ve stillerden oluştuğunu, kitlesel dağıtımın ise ölçek ekonomilerinin önemli rol oynadığı depolama ve ulaştırma eylemlerine işaret ettiğini belirtmektedir. Yazar, tanımına istinaden kültür endüstrileri kapsamına giren alanları; müzik, kitap ve dergi yayıncıllğı, televizyon ve radyo, moda, video oyunları olarak sinırlandırmaktadır.

Kültür endüstrileri ve yaratıcı endüstriler birbirinin yerine kullanılsa da (Peterson ve Anand, 2004; Thompson vd., 2007), "kültürel” sözcügüunden “yaratıcı" sözcügüne daha fazla yönelim olmaya başladığını belirten Galloway ve Dunlop (2007, s.18-19), bu eğilimin nedenini bilgi ekonomisine ve ülkelerin geliştirmekte oldukları yeni ekonomik politikalara bağlamaktadırlar. Kültür Endüstrileri kavramını birincil olarak; film, televizyon, yayıncılık ve müzik gibi ticari endüstri sektörlerini kapsaması için icat edilmiş, aynı zamanda popüler kültür öğelerini kitlelere ileten endüstriler olarak tanımlanmaktadır. Tabiatı gereği melez olmaları yaratıcı endüstrileri farklı bir konuma taşımaktadır; hem kültürel, hem hizmet odaklı, hem araştırma ve geliştirme temelli hem de kamu hizmeti yapan sektörlerin özelliklerinden oluşan mozaiksel bir bütündür (Cunningham, 2004, s.106-113).
Yaratıcılığın "yaratıcı endüstriler" alanında faaliyet gösteren tüm sektörlerin yapı taşı olduğunu ileri sürmek, sektörel farklılıklara ilişkin önemli bir takım ayrıntıların anlaşılmasının önünde engel oluşturmaktadır (Ooi, 2011, s.120-121). Örneğin, büyük ölçüde devlet fonlarına ya da bağışlara bağlı olan güzel sanatlarla kıyaslandığında, kitlesel eğlence sektörünün açık ara farkla ticari potansiyele sahip olduğu bilinmektedir. Yazar’a göre, "yaratıcı endüstriler" başlığ 1 altında geliştirilen stratejiler, güzel sanatlar alanının üzerinde ciddi anlamda baskı yaratarak, kar amacı gütmeyen düşünce yapısını değiştirmeye zorlamaktadır. Ticari işletmelerin kamuyla, kurumsal sosyal sorumluluk adı altında iletişime girdiğini ve değer yarattığını belirten yazar, benzer şekilde güzel sanatlar uygulamalarında da daha fazla ekonomik sorumluluk üstlenerek değer yaratabileceğini öne sürmektedir. Benzer şekilde Wi (2014, s.3), Amerikan Birleşik Devletlerinde 90'lı yıllardan itibaren gerçekleşen özelde görsel sanatlar, genelde sanat alanında, hükümetin desteğindeki dramatik düşüşle, neoliberal politikaların yaratıcı kesime pompalandığını belirtmektedir. Yazar, söz konusu hükümet desteğinin azalması neticesinde sanatsal yaratımda bulunan bireylerin, mikro düzeyde, kendi ağları aracılığıyla yürüttükleri bağışlarla girişimci ve inovatif davranmaları yönünde bir beklenti oluştuğunu ifade etmektedir.

Yarattığı katma değerin yanı sıra, yaratıcı endüstriler, birey-temelli ya da takım-temelli çalışmalara yatkın sektörler olarak dikkate alınmaktadır. Örneğin moda tasarım işleri ya da mimari işler, yaratıcı bir bireyin ya da grubun vizyonunu somutlaştırabilmek için takımlara ihtiyaç duymaktadır. Ancak, sanat eserleri ya da yayıncllık gibi alanlarda vizyoner ya da üretici aynı kişi olarak karşımıza çıkmaktadır. Yaratıcı endüstrilerin yalnızca bahsi geçen mevcut yaklaşımlarla ele alınmaması gerektiği, "yaratıcı endüstriler" şemsiyesinin altındaki farklı sektörlerin, gerekli desteği alabilmesi ve gelişebilmesi için yeni yaklaşımlara ihtiyaç duyduğu anlaşılmaktadır (Oakley, 2004, s.72). Bu bağlamda konu ile ilgili olarak, moda tasarım alanı anlamlı bir örnek teşkil etmektedir. Malem (2008, s.401), moda endüstrisinde başarılı olabilmek için güçlü bir iş nosyonu ile sanatsal çabaların el ele olması gerektiğini savunmaktadır. Moda endüstrisi dışında kalan, film endüstrisi, müzik endüstrisi, reklam endüstrisi gibi alanlarda da aynı ikili işleyişin (iş nosyonu ve sanatsal eğilimin) bir arada bulunmaları gerekliliğinin ön planda olduğu düşünülmektedir. 
Çünkü bireysel yaratıcılığın yanında, ticari bir şirketin de işin içine girerek, büyük sanatsal ve yönetim takımlarını birbirine entegre etmesi gerekmektedir.

Pratt (2005, s.35), temelde kültür endüstrileri ile yaratıcı endüstrilerin benzer noktalara temas ettiğini, ancak yaratıcı endüstriler kavramının Birleşik Krallık tarafından 1997 yılında yeni iş gücü yönetimi adı altında, eski işgücü değerlerinden kendilerini farklı bir şekilde konumlandırmak istedikleri için öne sürdükleri politik bir yorumlama olduğunu iddia etmektedir. Throsby (2010, s.8), kültür politikalarına ilişkin geniş bir tanımlama yaparak, kültürel pratiklerin ya da değerlerin; hükümetler, kuruluşlar, şirketler ve bireyler tarafından teşvik edilmesi olarak tanımlamaktadır. Benzer şekilde Newsinger (2015, s.303), yaratıcı endüstrileri, Birleşik Krallıkta neoliberal karakterdeki medya, kültürel ve teknoloji sektörlerinde kendini somut bir biçimde gerçekleştiren resmi bir politik söylem ve örgüt yapısı olarak nitelendirmektedir. Yeni bir politik yörünge olarak 1997'lerin sonlarında "Yeni İngiliz İş Gücü’nü" oluşturmak üzere kurgulanan kültür endüstrilerine ilişkin politikaların bir kısmının özellikle Avustralya tarafından takip edilmesiyle, İsviçre, Çin, Amerika gibi ülkelerinde katılımıyla yaratıcı endüstriler günümüzde önemli bir politik söylem haline gelmiştir.

Titan vd. (2008, s.930-931), kültür ekonomisi (economy of culture) başlığı altında kültürel ve yaratıcı endüstriler arasında ayrıma gitmektedirler. Yazarlara göre kültür endüstrileri tekrarlanamayan (konser, sanat festivali, sergi) ya da tekrarlanabilen (kitap, film, ses kaydı) gibi nihai tüketim ürünlerinden oluşmaktadır. Bu nedenle de, yayımcilık, film, video, radyo ve televizyon, sahne sanatları, basın yayın, müzecilik, arşivcilik, kütüphanecilik, kültürel ürünlerin toptan ve perakende satışlarının hepsi kültürel endüstriler bölümlemesinin altında yer almaktadır. Yaratıcı endüstrilerde ise, kültür üretim sürecinde değerlendirilmekte olup, yaratıcilık (bilgi, beceri, tecrübe) kültürel olmayan ürünlerin üretiminde bir girdi olarak işlev görmektedir.

Endüstri devriminin ana fikri olan sanayileşme ve bu sanayileşme sürecinde ürettikleri çıtıların netliğinden ötürü demir-çelik endüstrisi, otomobil endüstrisi, vb... endüstrileri tanımlanmakta ve konumlandırmakta zorluk yaşanmamaktadır. Ancak, taşıdığ sofistike karakter nedeniyle farklılık gösteren yaratıcı endüstrilerin, hem yaratıcılığın girdi özelliği taşımas1, hem de birincil (tarım ve madencilik), ikincil (üretim), üçüncül (hizmet) sektörlerin her birine uyum sağlamasından ötürü ne şekilde konumlandırılacağ 1 tartışma konusu olmaktadır. Bu karışıklığın giderilmesi için, yaratıcı endüstrilerin "deneyim ekonomisi” başlı̆̆ı altında konumlandırıldığı anlaşılmaktadır (Hartley, 2005, s.26).

\section{Yaratıcı Endüstrilerde Bilgi ve Yaratıcılık Bağlamında Özne Sorunsalı}

Bilgi ekonomileri bağlamında hem kavramsal hem de pratik anlamları içeren yaratıcı endüstriler; sanat, kültür endüstrileri ve bilgi iletişim teknolojilerinin oluşturduğu üçlü bir sarmalı ifade etmektedir. Yaratıcılık ve yetenek temelli işlerin bilgi iletişim teknolojileri aracılığıyla iletilmesi ve yaygın hale getirilmesi ile iletişim arenasının bir fonksiyonu olarak kendini gösteren yaratıcı endüstriler, bireysel yeteneğin bilgi iletişim teknolojileri aracılığıyla kitlesel ölçekte gerçekleştirmesine vurgu yapmaktadır (Hartley, 2005, s.5). Söz konusu iletişim arenası ve enstrümanları, kendi kabuğunda devinen yaratıcı bireyleri geniş kitlelerle buluşturma ya da bu buluşmanın sağlanacağ 1 platformları oluşturma işlevi görerek, yaratımın yaygınlaşmasının, tüketilmesinin ve yeniden üretilmesinin önünü açmaktadır.

Warhurst (2010, s.226), bilgi ve yaratıc1 ekonomilerin belirgin bir biçimde örtüştüklerini belirtmekle birlikte, bilgi ve yaratıcı ekonomileri birleştirmenin, yaratıcı ekonominin dayandığı estetik, kültürel ve tecrübeye dayanan ürün söylemlerini göz ardı etmek olduğunu ifade etmektedir. Bilgi yoğun malların, estetik özelliklerin egemen olduğu sembolik ürünler olmadığı, bu nedenle de sembolik ürünlerde teknik yaratıcılığın estetik yaratıcılık ile birleştirilmesinin zorunlu olduğu belirtilmektedir (Thompson vd., 2009, s.67). Benzer şekilde Allen (2002, s.50), sembollerin belirleyici olduğu estetik alanda, bilginin özel şekillerinin varlı̆̆ından söz etmenin mümkün olduğunu ileri sürmektedir. Söz konusu "alan" da; kelimelerin, imgelerin, seslerin göstergelerin dişavurumcu sistemlerinin birer fonksiyonu olarak işlevsellik kazandığı anlaşılmaktadır. Bu nedenle, yaratıcı endüstriler bağlamında üretilen bilginin, özel bir takım dışavu- 
rumcu semboller aracıllğıyla gerçekleştiğinden, bilgi ekonomisi kapsamında üretilen bilgiden daha farklı bir bilgi kategorisini ifade ettiğinin altını çizmek gerekmektedir.

Yukarıda bahsedilen ayrımlar büyük ölçüde, bilgi endüstrileri ve yaratıcı endüstrilerin epistemolojik ve ontolojik ayrımlarından kaynaklanmaktadır. Bilgi endüstrileri, büyük ölçüde kullanılması ve transfer edilmesi daha kolay olan kodlanabilir bilgiye dayanmaktadır. Bunun sonucu olarak da bilgi endüstrilerin ürettikleri çıktı "açık bilgi" olarak öne çıkmaktadır. Yaratıcı endüstriler ise büyük ölçüde, yaratıcı birey veya takım tarafından üretilen ve diğerleri tarafından kullanılmasının yanında kodlanması ve aktarılması güç olan "örtük bilgiye" dayanmaktadır. Ancak, günümüzde bilgi teknolojileri, post modern toplum, küreselleşme gibi nedenlerden ötürü, yaratıcı endüstrilerin oluşlarında süregelen bir melezleşmeden söz etmek anlamlı görünmektedir. Cunningham (2004, s.112), yaratıcı endüstrilerin; kültürel, hizmet temelli, ar-ge merkezli, kamu sektörü özelliklerini taşıyan melez bir yapı gösterdiğini ileri sürmektedir. Ayrıca yazar, yalnızca işgücünün ya da işin kendi doğasının değil, aynı zamanda varlık sebebinin de melez oldugunu, bu nedenle söz konusu endüstrilerin ekonomik ve rekabetçi kaygıları da taşıdığını belirtmektedir.

Mellander (2009, s.294), iş gören profili bakımından bilgi endüstrileri ve yaratıcı endüstriler ayrımına giderken, bilgi endüstrilerinin iyi eğitimli bireylerden, yaratıcı endüstrilerin ise yüksek düzeyde yaratıcıllğa sahip iş görenlerden oluştuğuna dikkat çekmektedir. Benzer şekilde Mercer'da (2009, s.294), bilgi ekonomilerinden yaratıcı ekonomilere doğru bir eğilim olduğunu ifade ederken, üstü kapalı olarak bilgi endüstrileri ve yaratıcı endüstrileri birbirinden ayırmakta, yaratıcı endüstrilerin yeni faaliyet alanları ve iş firsatları oluşturduğuna dikkat çekmektedir. Yazar tartışmasını daha da ileri götürerek, yaratıcı endüstrilere gösterilen yetersiz ilgiyi eleştirmekte ve söz konusu endüstrilerin yerel, bölgesel, ulusal ve küresel arenadaki stratejik önemine işaret ederek, sosyal ve ekonomik potansiyelinin daha iyi anlaşılması gerektiğini savunmaktadır.

Yaratıcı endüstriler literatüründe, "yaratıcı birey" ile ilgili sürmekte olan bir açmazın varlı̆̆ından söz edilmektedir (Chaston, 2008, s.820). Açmazın teme- linde, maddi kazanç ya da yaşam tarzına ilişskin alışkanlıklarda yatan bireysel tercihler yer almaktadır. Bu bağlamda, motivasyon maddi kazanç ise, yaratıcı birey pazardaki talebi çok iyi okumak durumunda; şayet değilse, o zaman yaratıcı bireyin kendi arzularını gerçekleştirmesini sağlayan iç motivasyondan ve özgürlükten bahsetmek mümkün olmaktadır. Christophersen (2008, s.74), yaratıcı kariyerin tam merkezinde yer alan bireyin -kendi kendini ifade edebilen girişimci- yaratıcı beceriler ve kendini ifade etme becerileri ile ekonomik motivasyondan yola çıan sıkıcı işler ikililiği üzerinden kendini gerçekleştirdiğini belirtmektedir. Yazara göre yaratıcı iş görenlerin anahtar tutumları, değişim karşısında gerçekleştirdikleri uyumlaşabilme ve esneklik becerileri olarak öne çıkmaktadır. "Bireysel yaratıcılığı" kendi antitezi olan "yönetim” olgusuna karşı olduğunu ifade eden görüşü romantik bir kalıp yargı olarak niteleyen Bilton (2007), yaratıcilığın bireysellikten öte kolektif ve sistematik olabileceğine, aynı zamanda yaratıcı ve yaratıcı olmayan iş gören sınıflamasının zorluğuna işaret etmektedir. Yazar, yaratıcı işin rutinleri olduğu gibi rutin işlerin de yaratıcı elementler içerdiğini ileri sürerek, kavramların sınırlarını çizmede ki zorluğa işaret etmektedir.

Florida (2003, s.7), yaratıcı sermayenin aktörlerini yaratıcı sinıf (creative class) olarak tanımlayarak, bu özellikli sınıfa, anlamlı yeni formların mimarları vasfını yüklemektedir. Tezini ilerleten yazar, yaratıcı sınıfı kategorilere ayırmaktadır. Süper-yaratıcı çekirdek (super-creative core) kategorisinde; bilim insanları, üniversite profesörleri, şairler, yazarlar, sanatçılar, göstericiler, aktörler, tasarımcılar, aynı zamanda modern toplumun fikir liderleri olan, bilim kurgu yazarları, editörler, kültür şahsiyetleri, düşünce kuruluşları araştırmacıları, analizciler yer almaktadır. Bu sinifta yer alan bireyler, transfer edilebilen ve oldukça kullanışlı yeni formlar ve tasarımlar üretmektedirler. Diğer bir sınıf olan yaratıcı profesyoneller (creative professionals) kategorisinde, daha çok yüksek teknoloji enstitüleri, finansal hizmet sektörü, yasal ve sağlık sektörü çalışanları ve işletme yönetimi gibi bilgi-temelli işlerde çalışan bireyler yer almaktadır. Bu bireyler yaratıcı problem çözme süreçlerinde karmaşı bilgi kaynaklarından yararlanmaktadırlar. Yaptıkları iş doğası gereği yoğun bilgi gerektirdiğinden, yaratıcı profesyoneller formel eğitimli insan sermayesi olarak değerlendirilmektedirler. 
Yaratıcı endüstriler; yetkiyi paylaşmanın, esnekliğin, bilgi temelli üretim sistemlerinden dolayı Peter'ın (1992), "özgürleşmiş firma- liberated firm” nosyonuna örnek oluşturmaktadır (Hodsgon ve Briand, 2013, s. 309). Bilton (2007, s. 173), benzer bir şekilde, yaratıcı endüstriler kavramının, eski ekonomi karşısında yeni ekonomiyi konumlandırarak meşrulaştırılması olduğunu ifade etmektedir. Söz konusu yeni ekonomi, yeni işletme modelleri ve örgüt yapıları aracıl1ğıla beslenmektedir ki; bu işletmeler serbest meslek, otonomi, esneklik, oldukça nitelikli işgücü ve kendi kendine motive bağımsız çalışan bireylerden oluşmaktadır.

Florida (2002, s.48), yaratıcı endüstrileri tanımlarken risk sermayesi finansmanı, modüler üretim ve yarat1c1lığ tetikleyen bir sosyal ortam özelliklerine vurgu yaparak, söz konusu endüstrilerde iş sözleşmelerinin de farklılık göstererek, iş görenlerin otonomi ve özgürlügü seçtikleri için, uzun dönemli sözleşmeler yerine kısa dönemli sözleşmeleri tercih ettiklerini vurgulamaktadır. Benzer şekilde Thompson vd. (2009, s.53), entelektüel varlıkların doğaları gereği, endüstri toplumunun geleneksel hiyerarşik yapı ve pratikleri reddettiklerini belirterek, yaratıcı iş gören sinıfının bağımsızlı̆̆ının peşinde olduğuna ilişkin yaygın bir görüş olduğunu öne sürmektedirler

Banks ve Hesmondhalgh (2009, s. 416) "yaratıc1 emek" kavramını, fonksiyonel ya da faydacı olmak$\tan$ öte, öncelikli olarak estetik ya da sembolik ifadeye dayalı orijinal ya da karakteristik malların ve hizmetlerin üretimine bağlı olan emek olarak ifade etmektedirler. O’Brien ise “yaratıcı emek” kavramını daha bütüncül bir perspektiften ele alarak, tarihsel süreçte ne anlam ifade ettiği üzerinden çözümleme yapmaktadır. Yazar’a göre, “yaratıcı emek”, yirminci yüzyılda ideal işgücü şeklini temsil ederken, yirmi birinci yüzyılda post-fordist, post-endüstriyel batılı ekonomilerin yaşamakta olduğu bir takım stratejik politikalarda gömülü anlamları karşılamaktadır. Bu bağlamda yaratıcı emek, ekonomik anlamda değer yaratma potansiyeline sahip çekici bir vizyon olarak öne çıkmaktadır (O’Brien, 2014, s. 52).

\section{Yaratıcı Endüstriler Taksonomisi}

Birleşmiş Krallık, Kültür Medya ve Spor Departmanı yaratıcı endüstrileri; fikri mülkiyetin işletilmesi ile iş ve refah yaratma potansiyeli oluşturan, bireysel yaratıcılığa, beceriye, yeteneğe dayanan endüstriler şeklinde tanımlamaktadır. Bununla birlikte, yaratıcı endüstrileri oluşturan sektörler şu şekilde sıralanmaktadır; reklamcılık, mimarlık, sanat ve antika pazarı, el sanatları, tasarım, moda tasarım, film ve video, interaktif serbest zaman yazılımları, müzik, sahne sanatları, yayımcılık, yazılım ve bilgisayar hizmetleri, televizyon ve radyo (DCMS, 2001). Melchior vd., (2011, s.216), yaratıcı endüstriler kavramının kültürden kültüre nasıl değiştiğine dair önemli örnekler vermektedirler. Örneğin, Birleşmiş Krallık moda sektörünü yaratıcı endüstriler başlığ 1 altına alırken, Danimarka moda sektörünü kültürel ve deneyim ekonomisi başlığı altında değerlendirmektedir. Bu bağlamda yazar, iki ülke arasında kavrama ilişkin yalnızca kapsam arasında değil, politika farklılıklarının da mevcut olduğunun altını çizmektedir.

Yaratıcı endüstrilerin sınıflandırılması, paydaşlar tarafından (UNESCO, DCMS, WIPO) sektörlerin birbirlerinden farklı kategoriler altında değerlendirilmesi nedeniyle bağımsız olarak yapılmakta ve nasıl ele alınacağına ilişkin sorunları da beraberinde getirmektedir. Örneğin, Birleşmiş Milletler Ticaret ve Kalkınma Örgütü (UNCTAD); "üretime dönük aktiviteler" ile geleneksel kültürel aktiviteleri bir grupta (sahne sanatları ya da görsel sanatlar gibi) ve "satışa dönük aktiviteler" ile pazara daha dönük aktiviteleri (reklamcılık, yayımcılık ya da medya ilişkili aktiviteler) diğer bir grupta toplamaktadır. Söz konusu ayrımda satışa dönük aktivitelerin ticari değerinin düşük olmasını, yeniden üretme maliyeti ve ekonomik alana daha kolay transfer edilebilmesinden kaynaklandığını öne sürmektedir. Diğer yaklaşımlar yaratıcı endüstrileri farklı kategoriler altında tanımlamakla birlikte, geleneksel sanatları, hatta mutfak sanatlarını dahi yaratıcı ekonominin içine dahil etmektedirler. Birleşmiş Milletler Ticaret ve Kalkınma Örgütü (UNCTAD), 2010 yılında sundukları Yaratıcı Ekonomi Raporu'nda, yaratıcı endüstrileri bazı özelliklerine göre tanımlamaktadırlar; örneğin yaratıcı ve entelektüel sermaye bu sektörlerdeki birincil girdidir ve bilgi-temelli bazı aktivitelere dayanmaktadır. Yaratıcı içerikli sanatsal hizmetler, zanaat-hizmet-endüstri- 
yel sektör üçgeninin kesişim noktasında yer almakta, ekonomik değer ve pazar hedeflerine göre şekillenerek dünya ticaretinde yenilik vadeden dinamik bir sektör oluşturmaktadır.
Santagana vd. (2009, s.30), yaratıcı ve kültürel endüstrilerini 3 ana sektöre; materyal kültür (moda, endüstriyel tasarım, el sanatları, yiyecek ve şarap endüstrisi), içerik üretimi, bilgi ve iletişim (bilgisayar

Tablo 1. Yaratıcı Endüstriler Sınıflandırması

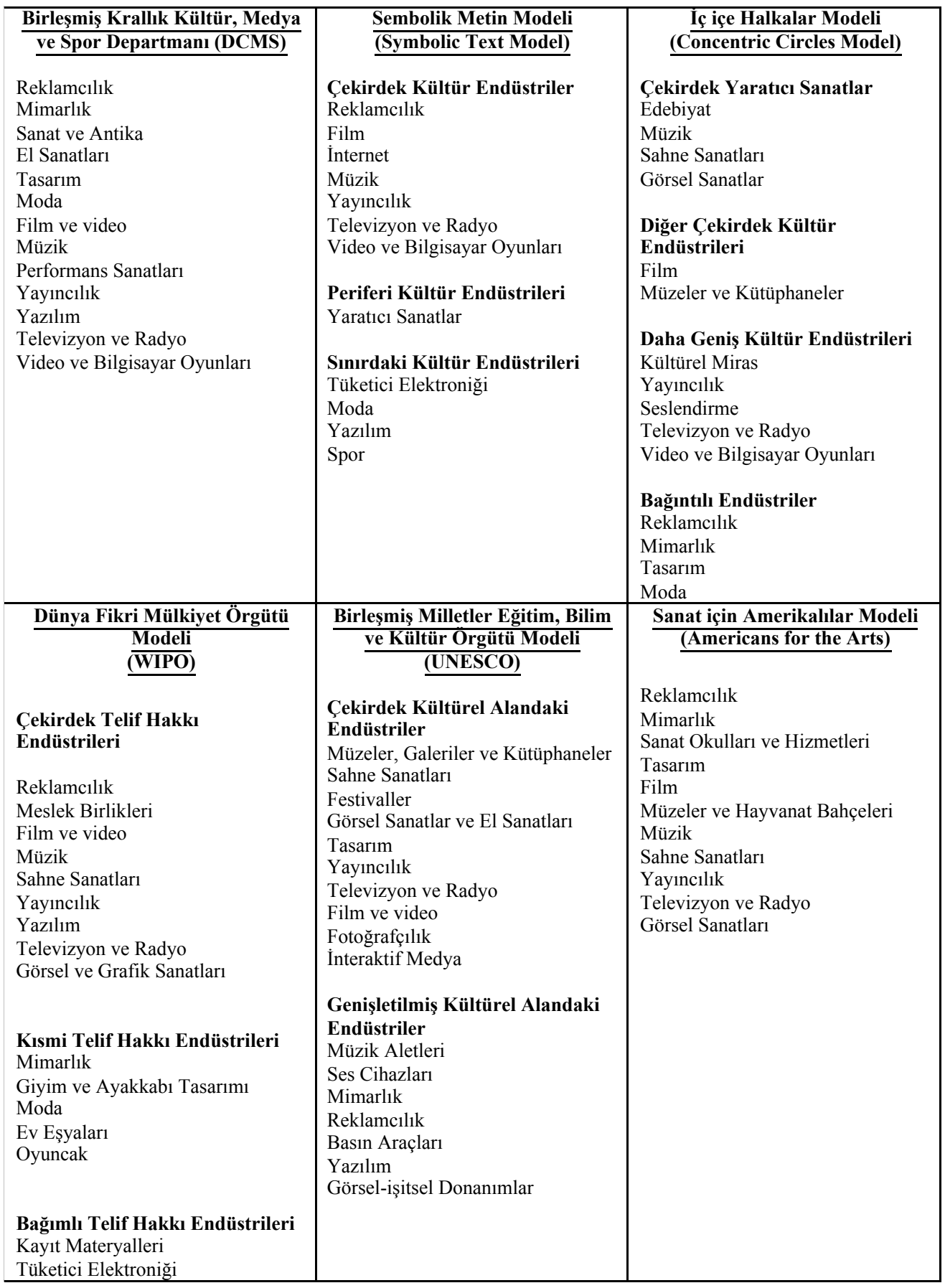

Kaynak: 2013 Yaratıcı Ekonomi Raporu’ndan yazarlar tarafından genişletilmiştir 
Tablo 1. Yaratıcı Endüstriler Sınıflandırması (Devamı)

\begin{tabular}{|c|c|c|}
\hline $\begin{array}{l}\frac{\text { Birleşmiş Milletler Ticaret ve }}{\text { Kalkınma Konferansı }} \\
\text { (UNCTAD) } \\
\text { Kültürel Miras } \\
\text { Geleneksel Kültürel Anlatımlar } \\
\text { Kültürel Alanlar } \\
\text { Sanat } \\
\text { Görsel Sanatlar } \\
\text { Sahne Sanatları } \\
\text { Medya } \\
\text { Basım ve Yayıncılık } \\
\text { Görsel işitsel } \\
\text { Fonksiyonel Yaratımlar } \\
\text { Tasarım } \\
\text { Yeni Medya } \\
\text { Yaratıcı Hizmetler }\end{array}$ & $\begin{array}{l}\frac{\text { Ulusal Bilim Teknoloji ve Sanat }}{\text { Ulusal Vakfı }} \\
\text { (NESTA) } \\
\text { Yaratıcı Hizmet Sağlayıcıları } \\
\text { Reklam Ajansları } \\
\text { Tasarım Danışmanlıkları } \\
\text { Yeni Medya Ajansları } \\
\text { Yaratıcı İçerik Üreticileri } \\
\text { Film, Televizyon ve Tiyatro } \\
\text { Prodüksiyon Firmaları } \\
\text { Bilgisayar ve Video Oyunları } \\
\text { Geliştirme Stüdyoları } \\
\text { Kitap ve Dergi Yayıncıları } \\
\text { Moda Tasarımcıları } \\
\text { Yaratıcı Deneyim Sağlayıcıları } \\
\text { Tiyatro, Opera ve Dans } \\
\text { Prodüksiyon Firmaları } \\
\text { Canlı Müzik Organizatörleri } \\
\text { Yaratıcı Kaynak Üreticileri } \\
\text { Görsel Sanatlar } \\
\text { Tasarım Üretici } \\
\text { El Sanatları }\end{array}$ & $\begin{array}{l}\qquad \frac{\text { Kern Avrupa İșleri }}{\underline{\text { (KEA) }}} \\
\text { Çekirdek Sanat Alanları } \\
\text { Görsel Sanatlar } \\
\text { Sahne Sanatları } \\
\text { Kültürel Miras } \\
\text { Kültürel Endüstriler } \\
\text { Film ve Video } \\
\text { Televizyon ve Radyo } \\
\text { Video Oyunları } \\
\text { Müzik } \\
\text { Kitap ve Yayıncıllı } \\
\text { Yaratıcı Endüstriler } \\
\text { Tasarım } \\
\text { Mimarlık } \\
\text { Reklamcılık } \\
\text { İlişkili Endüstriler } \\
\text { Bilgisayar Üreticileri } \\
\text { Cep telefonu Endüstrisi }\end{array}$ \\
\hline $\begin{array}{l}\quad \frac{\text { Avustralya Ulusal Bilgi }}{\text { Ekonomisi Ofisi }} \\
\qquad \frac{\text { (NOIE) }}{} \\
\text { Reklamcılık } \\
\text { Mimarlık } \\
\text { Tasarım } \\
\text { İnteraktif Yazılım } \\
\text { Film ve Televizyon } \\
\text { Müzik } \\
\text { Yayincilık } \\
\text { Sahne Sanatları }\end{array}$ & & \\
\hline
\end{tabular}

ve yazılım, yayıncilık, radyo ve televizyon, reklam ve film endüstrisi), kültürel ve sanatsal miras (kültürel miras, müzik ve sahne sanatları, mimarlık, çağdaş sanat) ayırmaktadırlar. Bu ayrımda yaratıcı endüstrilerin, klasik kültürel aktiviteler ile iletişim araçları temelinde şekillenen üretim alanlarını kapsayan aktiviteler olarak sınıflandırıldığı anlaşılmaktadır. Ancak, on farklı sinıflamanın yapıldığı Tablo 1' de görüldüğü üzere, neredeyse her bir sinıflamanın içinde kültür, kültür endüstrisi, kültürel aktiviteler gibi içinde "kültür" kelimesinin yer aldığ terminolojiye yer verilmektedir. Bu bağlamda, kültür ve yaratıcı endüstrilerin iç içe geçmiş oldukça karmaşık bir yapı sergiledikleri anlaşılmaktadır.
Brouillette (2008, s.122), yaratıc1 endüstrilerin postendüstriyel ekonomi ve politik bir takım eğilimlerle aynı eksende yer aldığını belirterek; kültürün amaca uygunluğu (Yúdice), ekonominin üretimci güçleri ile toplumun kültürel kapasitesi arasındaki yakın ilişkiyi ifade eden enformasyonel yöntem (Castells), ya da bilgi temelli girişimlerin yeni medya teknolojileri ile biçimlendiği matris (Hartley) şeklinde farklı yazarlar ve görüşler çerçevesinde yorumlandığını belirtmektedir. Tablo 1. incelendiğinde, yaratıcı endüstriler kavramının farklı yazar, düşünce kuruluşları ve politik görüşler çerçevesinde şekillendiği görülmektedir. Örneğin Nesta, yaratıcılık temelinden hareket ederek bir sınıflandırmaya giderken, Sembolik Metin 
Modeli, kültür endüstrilerinin üzerinden söz konusu sinıflandırmayı yapmaktadır. Bu bağlamda, yaratıcı endüstriler kavramının bağlam ve varılmak istenilen nokta doğrultusunda yeniden yapılandırılarak sınıflandırıldığı anlaşılmaktadır.

Galloway ve Dunlop (2007, s. 28-29), yaratıc1 endüstrilere ilişkin söylemleri, matruşka bebeklere benzetmektedirler; özüne doğru açıldıkça belirli bir kültürel bağlamdan kopan sinırları belli olmayan bir varlığa dönüşmektedir. Bu metaforu yerinde bir benzetme olarak değerlendiren Newsinger (2015, s. 311), yaratıcı endüstrilerle ilgili geliştirilen politikaların dönüşümünü, devletlerin güttükleri tasarruf yaklaşımları doğrultusunda kültürel bağlamdan gittikçe uzaklaşmaları ile açıklamaktadır. Galloway ve Dunlop’a göre (2007, s. 29), kültürel aktiviteleri yaratıcı ya da bilgi ekonomileri çatısı altına almak, kültürel politikaların yaşamsallıklarının anlaşılmasını engelleyerek, kültürel aktivitelerin halkın yararına sağladığı faydayı gölgelemektedir. Hatta yazarlar, ekonomik ajanda bağlamında oluşturulan yaratıcı endüstriler kavramının bir alt sınıfı olarak kültür endüstrilerini pazar aracılığıyla değerlendirmenin, yarattığı değerin anlaşılamamasina neden olduğunu iddia etmektedirler. Ancak burada, kültürel aktivitelerin kamu yararından koparılarak, post-kapitalist söylem ve neoliberal ekonomik politikalar içinde yeniden üretiliyor olarak algılanması çok radikal bir görüş olarak değerlendirilmektedir. Söz konusu radikal görüş yerine yaratıc1lığın yeni bir söylemle inşasından bahsetmenin, araştırmacıların ve politika uygulayıcıların önünü açan daha yapııı bir yaklaşım olduğu savunulmaktadır.

\section{Sonuç ve Tartışma}

Yaratıcı endüstrilere ilişkin ilk analog çalışmanın aslında Schumpeteryan "yaratıcı yıkım" kavramı ile dile getirildiğini belirten Hartley (2014, s. 94-95), küresel platformda dijital çevrimiçi ağların gelişmesi ile geniş kitleler tarafından kavramın bilinirlik kazandığını öne sürmektedir. Yaratıcı endüstrilerin evrimleşmesini tetikleyen itici gücü; telifli sanat ve medyanın, kendi kendini pazarlayabilen dijital ağlara dönüşmesi ile açlklayan yazar, YouTube, Facebook, Wikipedia, Twitter gibi sosyal paylaşım sitelerinin, kullanıcının kendi içeriğini yaratmasına izin vermesiyle popüler ve küresel bir değişim aracı olarak göstergelerini yeniden inşa ettiğini belirtmektedir. Bu yaklaşım, yaratıcılıkla ilgili unsurların, ağlar aracılığıyla yeniden yapılandırılarak kendine daha geniş bir zemin yarattığını ve yayılmasının hızlandığına vurgu yapmaktadır. Gerçekten de bilgi iletişim teknolojileri ile yaygınlaşan yaratıcılık, yalnızca kültürel, sanatsal bir kullanımdan öte ekonomik anlamda da önemli bir yer teşkil etmektedir.

Yaratıcı endüstriler kavramının gerek girdi gerekse çıktıları bakımından kültür endüstrilerinden ayrıştırma gereği önem arz etmektedir. Kültürel ürünler; fayda fonksiyonundan ziyade estetik ya da dişavurumcu maddi olmayan özelliklerin ön planda olduğu, kamunun tüketimine açılmış ürünlerken (Hirsch, 1972, s.641); yaratıcı endüstrilerin çıktıları olan ürün ve hizmetlerin hem fonksiyonel hem de estetik anlamda ekonomik ve kültürel özellikleri bir arada taşıması beklenmektedir. Bu yönleri ile her ne kadar Frankfurt Okulu üyelerinin yaptıkları kültürün endüstrileşmesinin iletişim teknolojileri aracıllğıyla gerçekleştiği yönündeki görüşlerine benzese de, yaratıcı endüstrilerin kavramsallaştırıldığı dönem ve söz konusu endüstrilerin kullandıkları teknolojik yöntemlerin farklı olduğu anlaşılmaktadır. Ayrıca, kültür endüstrileri kavramı, eleştirel bir bakış ve onun çıktısı olarak somutlaşırken, yaratıcı endüstriler neoliberal söylemlerle, sanatın ve yaratıcılığın daha fazla ekonomik motivasyonla ele alınması gerekliliğinin altını çizmektedir. Bu bağlamda da kültür endüstrileri ile yaratıcı endüstriler farklı söylemler ve çözümlemeler üzerinden hareket etmektedirler. Benzer bir anlayışla, Banks ve O'Connor (2009, s.366), yaratıc1 endüstrilerin; özel bir ekonomik gruplandırma, belirli bir entelektüel ya da sanatsal işgücünü çerçevelendirme veya en basit ifadeyle politik bir yapı olarak tanımlayarak, kültür endüstrileri ve yaratıcı endüstrilerin ayrımını netleştirmektedir.

Yaratıcı endüstriler, entelektüel sermaye ve kültürel kaynaklar aracılığıyla değer ve iş alanları yaratan ve semiyotik değerlerle karakterize edilen ekonomik sektör olarak tanımlanmaktadır （Wai, 2006, s.333334). Bu semiyotik değerler, geleneksel olarak tüketilen faydacı değerlerden farklı olarak estetik zevkleri işaret eden, sembolik ya da faydacı olmayan değerleri bünyesinde barındırmaktadır (Townley vd., 2009, s.940). Ancak, yaratıcı endüstriler kavramının içini doldurmak için söz konusu semiyotik değerlerin de ekonomik olarak bir karşıllı̆ının olması beklenmektedir. Aksi takdirde, yaratıcı endüstriler yalnızca 
kamu yararına üretim yapan üçüncü sektör ile eşdeğer konuma geleceğinden, devlet teşvikleri ile ayakta kalan kültürel sektörler ile yaratıcı sektörlerin aralarındaki farklılığı ortaya koymak imkansızlaşmaktadir. Bu bağlamda Hawkins'in (2001, s.126-127), yaratıcilık kavramı ile ekonomi kelimesini oksimoron olduğu için yan yana getirmekten imtina eden kişileri eleştirerek, söz konusu kavramlar arasında tansiyonun dengelenmesi gerekliliğine dair eleştirisi önem kazanmaktadır. Çünkü yazara göre yaratıcılık, içinde bulunduğumuz yüzyılda ekonomi kavramı ile yakından ilişkilidir ve bu iki kavramı birbirinden ayırmak anlamlı bir çaba gibi görünmemektedir.

Ekonomik perspektiften değerlendirildiğinde, yarat1$\mathrm{Cl}$ endüstrilerin mikro ve makro düzeyde katma değer yarattığı anlaşılmaktadır. Yaratıcı endüstriler teorisi, yalnızca inovasyon aracıllğıyla gerçekleşen ekonomik kalkınmanın değil, aynı zamanda hizmet sektöründe gerçekleşen evrimsel olguyu da açıklamaktadır. Ancak yine de yaratıcı endüstriler teorisi, iletişim ağ kabullenme, örgütlenme ve koordinasyon gibi ekonomik kalkınmanın çok önemli olan sosyal yönlerini de işaret etmektedir (Potts, 2009, s.664). Kimpeler ve Georgieff (2009, s.209), yaratıc1 endüstrileri; yenilikçi iş alanları oluşturmaları ve farklı sektörlerde faaliyet gösteren firmalara yeni fikirler aktaran tedarikçiler gibi davranmaları nedeniyle, yarattığı katma değer bakımından iki başlık altında toplamaktadır. $\mathrm{Bu}$ bağlamda hem kendi sektörlerinde baş aktörler hem de diğer sektörlerde yardımcı aktörler olarak değer yarattıkları anlaşılmaktadır.

O’Connor (1999, s.1), yaratıcı endüstriler kavramının hem akademik hem de politik çevreler tarafından ilgi çekici bir konu olarak ele alınmasına rağmen, az sayıda geliştirilen teorik ve politik modelin varlığından söz edilebileceğine dikkat çekmektedir. Gerçekten de söz konusu endüstrilere ilişkin geliştirilen yenilikçi iş modelleri, bu endüstrilere dair girişimci eğilimler, stratejik anlamda nasıl yönetildikleri, iş gören ve işveren yapısındaki karmaşık oluşumlar, yaratıcı endüstrilerde örgüt davranışı gibi alanlarda çalışmalara büyük ihtiyaç duyulmaktadır. Yaratıcı endüstriler alanının iletişim, kültür çalışmaları, yönetim, sanat gibi birden çok akademik disiplini ilgilendiren bir konu olması nedeniyle, bu alanlardan birkaçında yetişmiş araştırmacıların ya da multidisipliner araştırma gruplarının konuyla ilgili alan çalışması, vaka analizi, söylem çalışmaları yapmaları gerekmektedir. Yaratıcı endüstriler alanı multidisipliner doğası gereği, farklı yöntemlerin uygulanması için elverişli bir ortam hazırlamaktadır. Araştırmacıların içerik ve bağlamı dikkate alarak, bu bakir alanı hem teori geliştirmek hem de politika yapıcılara anlamlı uygulama stratejileri sağlamak için harekete geçmeleri önemle tavsiye edilmektedir.

\section{Kaynakça}

Allen, J. (2002). Symbolic Economies: the "culturalization of economic knowledge". Paul du Gay ve Michael Pryke (Ed.), Cultural Economy içinde (s. 39-58). London: Sage.

Banks, M., Hesmondhalgh, D. (2009). Looking for work in creative industries policy. International Journal of Cultural Policy, 15(4), 415-430.

Banks, M., O'Connor, J. (2009). Introduction: After the creative industries. International Journal of Cultural Studies, 14(4), 365-374.

Bilton, C. (2007). Management and Creativity: From Creative Industries to Creative Management. Oxford: Blackwell.

Brouillette, S. (2008). Contemporary Literature, PostIndustrial Capital, and the UK Creative Industries. Literature Compass, (5/1), 122-133.

Castells, M. (1994). European Cities, the Informational Society, and the Global Economy. New Left Review (1/204), 18-32.

Caves, R. E. (2000). Creative Industries: Contracts between Art and Commerce. Cambridge: Harvard University Press, MA.

Chaston, I. (2008). Small creative industry firms: a development dilemma?. Management Decision, 46(6), 819-831.

Csikszentmihalyi, M. (1988). Society, culture, and person: A systems view of creativity. Robert Sternberg (Ed.), The nature of creativity içinde (s. 325-339). Cambridge: Cambridge University Press. 
Christopherson, S. (2008). Beyond the self-expressive creative worker: An industry perspective on entertainment media. Theory Culture Society, 25 (7/8), 73-95.

Cunningham, S. (2001). From cultural to creative industries, theory, industry and policy implications. Culturelink, Special Issue, 19-32.

Cunningham, S. (2004). The creative industries after cultural policy. International Journal of Cultural Studies, 7 (1), 105-115.

DCMS, (2001). Creative Industries Mapping Document. Department for Culture, Media and Sport, London.

Florida, R. (2002). The Rise of The Creative Class. Basic Books, New York, NY.

Florida, R. (2003). Cities and creative class. City \& Community, 2 (1), 3-19.

Galloway, S., Dunlop, S. (2007). A critique of definitions of the cultural and creative industries in public policy. International Journal of Cultural Policy, 13(1), 17-31.

Garnham, N. (2005). From cultural to creative industries. International Journal of Cultural Policy, 11(1), 15-29.

Hartley, J. (2005). Creative industries. John Hartley (Ed.), Creative Industries içinde (s. 1-41). London: Blackwell Publishing.

Hartley, J. (2014). Urban semiosis: Creative industries and the clash of systems. International Journal of Cultural Studies, 18(1), 79-101.

Hirsch, P. M. (1972). Processing fads and fashions: an organization-set analysis of cultural industry systems. The American Journal of Sociology, 77(4), 639-659.

Howkins, J. (2001). The Creative Economy: How People Make Money from Ideas, London: Penguin Books.
Heelas, P. (2002). Work Ethics, Soft Capitalism and the "Turn to Life". Paul du Gay ve Michael Pryke (Ed.), Cultural Economy içinde (s. 78-96). London: Sage.

Hesmondhalgh, D., Baker, S. (2008). Creative work and emotional labour in the television industry. Theory, Culture \& Society, (25/7-8), 97-118.

KEA European Affairs (2006). Economy of Culture in Europe. Brussels: Directorate-General for Education and Culture, European Commission.

Kimpeler, S. Georgieff, P. (2009). The roles of creative industries in regional innovation and knowledge transfer: The Case of Austria. Ernesto Villalba (Ed.), Measuring Creativity: The Book. içinde (s. 207-219). European Commission.

Leadbeater, C., Oakley, K. (1999). The Independents: Britain's New Cultural Entrepreneurs. London: Deamos.

Malem, W. (2008). Fashion designers as business: London. Journal of Fashion Marketing and Management, 12(3), 398-414.

Matheson, B. (2006). A culture of creativity: design education and the creative industries. Journal of Management Development, 25(1), 55-64.

McRobbie, A. (2005). Clubs to Companies. John Hartley (Ed.), Creative Industries içinde (s. 375-390) Malden, MA: Wiley-Blackwell.

Melchior, M. R., Skov, L., Csaba, F. F. (2011). Translating fashion into Danish. Culture Unbound, (3), 209-228.

Mellander, C. (2009). Creative and Knowledge Industries: An Occupational Distribution Approach. Economic Development Quarterly, 23(4), 294-305.

Mercer, C. (2009). Convergence, creative industries and civil society: Towards a new agenda for cultural policy and cultural studies. Culture Unbound, (1), 179-204. 
Newsinger, J. (2015). A cultural shock doctrine? Austerity, the neoliberal state and the creative industries discourse. Media, Culture \& Society, 37(2), 302313.

NOIE (2003). Creative Industries Cluster Study. National Office for the Information Economy, Department of Communications,IT and the Arts, Canberra; http:// www.govonline.gov.au/publications/ NOIE/DCITA/ cluster_study_report_28may.pdf.

Oakley, K. (2004). Not So Cool Britannia: The Role of the Creative Industries in Economic Development. International Journal of Cultural Studies, 7(1), 6777.

O'Brien, D. (2014). Cultural Policy: Management, value and modernity in the creative industries. New York: Routlege.

O'Connor, J. (1999). The Definition of "Cultural Industries". [online], available at: http:// www.mipc. mmu.ac.uk/iciss/reports/defin.pdf (erişim tarihi 15.01.2016).

Ooi, C. (2011). Subjugated in the creative industries: The Fine Arts in Singapore. Culture Unbound, (3), 119-137.

Peltoniemi, M. (2015). Cultural Industries: ProductMarket Characteristics, Management Challenges and Industry Dynamics. International Journal of Management Reviews, 17(1), 41-68.

Peterson, R. A., Anand, N. (2004). The production of culture perspective. Annual Review of Sociology, 30, 311-334.

Potts, J. (2009). Why creative industries matter to economic evolution. Economics of Innovation and New Technology, 18 (7/8), 663-673.

Pratt, A. C. (2005). Cultural Industries and Public Policy: An Oxymoron?. International Journal of Cultural Policy, 11(1), 31-44.
Santagata, W, Bertacchini, E., Borrione, P. (2009). Culture, creativity and industry: An italian model. Walter Santagata (Ed.), White Paper on Creativity: Towards an Italian Model of Development içinde (s. 14-41). Milano: Università Bocconi Editore.

Simonton, D. K. (2000). Creativity: Cognitive, personal, developmental, and social aspects. American Psychologist, 55(1), 151-158.

Sternberg, R. J., Lubart, T. I. (1999). The Concept of Creativity: Prospects and Paradigm. Robert Sternberg (Ed.). Hanbook of Creativity içinde (s. 3-15). NY: Cambridge University Press.

Teipen, C. (2008). Work and employment in creative industries: the video games industry in Germany, Sweden and Poland. Economic and Industrial Democracy, 29(3), 309-335.

Thompson, P., Jones, M., Warhurst, C. (2009). From conception to consumption: creativity and the managerial missing link. Alan McKinlay, Chris Smith (Ed.), Creative Labour: Working in the Creative Industries içinde (s. 51-71). London: Palgrave.

Throsby, D. (2010). The Economics of Cultural Policy. Cambridge: Cambridge University Press.

Titan, E., Voineagu, V., Todose, M. (2008). The impact of cultural-creative industries on the economic growth-a quantitative approach. The Journal of the Faculty of Economics University of Oradea, 2(1), 930-935.

Townley, B., Beech, N., McKinlay, A. (2009). Managing in the creative industries: Managing the motley crew. Human Relations, 62(7), 939-962.

Turok, I. (2003). Cities, Clusters and Creative Industries: The Case of Film and Television in Scotland. European Planning Studies, 11(5), 549-565.

UNCTAD (2010). Creative Economy Report. Retrieved from http://www.unctad.org/Templates/webflyer. asp? docid=14229\&intItemID=5763\&lang=1\&mo de $=$ downloads. 
Von Osten, M. (2007). Unpredictable outcomes: A reflection after some years of debates on creativity and creative industries. Geer Lovink ve Ned Rossiter (Ed.). My Creativity Reader: A Critique of Creative Industries içinde (s. 49-59). Amsterdam: Institute of Network Cultures.

Wai, M. K. (2006). In search of the market in China: The regional dimension of Hong Kong's creative industries. International Journal of Cultural Studies, 9(3), 333-345.

Warhurst, C. (2010). The missing middle: management in the creative industries. Barbara Townley ve Nic Beech (Ed.), Managing Creativity: Exploring the Paradox içinde (s. 217-236). Cambridge: Cambridge University Press.
Win, T. S. (2014). Marketing the Entrepreneurial Artist in the Innovation Age: Aesthetic Labor, Artistic Subjectivity, and the Creative Industries. Antropology of Work Review, 35(1), 2-13.

Yúdice, G. (2003). The Expediency of Culture: Uses of Culture in the Global Era. Durham, NC, USA: Duke University Press 